\title{
Comparison of parathyroid hormone kinetics in endoscopic thyroidectomy via bilateral areola with open thyroidectomy
}

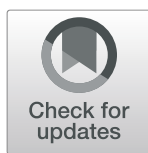

Daqi Zhang ${ }^{1}$, Tie Wang ${ }^{1}$, Gianlorenzo Dionigi², Jiao Zhang ${ }^{1}$, Yishen Zhao ${ }^{1}$, Gaofeng Xue ${ }^{1}$, Nan Liang ${ }^{1 * \dagger}$ and Hui Sun ${ }^{1 *+}$ (D)

\begin{abstract}
Background: In this study, we aimed to compare the kinetics of intact parathyroid hormone (iPTH) during the perioperative period of endoscopic thyroidectomy via bilateral areola approach (ETBAA) in the same period, following a traditional open thyroidectomy approach (OTA).

Methods: We conducted a prospective observational study of patients who were undergoing thyroidectomy and level VI clearance. Patients who had been affected by papillary thyroid cancer (PTC) were stratified into three groups: those eligible for endoscopic treatment (ETBAA); patients who were eligible for ETBAA but had opted for OTA (OTA-L); and patients who were not suitable for endoscopic intervention (OTA-H). A process for locating parathyroid glands was utilized to stratify gland dissection laboriousness. In Type A, the gland is firmly fixed to thyroid gland. This type can be sub-classified into three subtypes. A1: the parathyroid gland is attached to the inherent thyroid capsule. A2: the gland is partially embedded in the thyroid gland. A3: the gland is located in the thyroid tissue. Type B is defined as a gland which is separated from the thyroid gland. The iPTH was sampled at wound closure.

Results: There were 100 patients in each group. We found a significant difference between the ETBAA and OTA-H groups for type A2, as well as a loss of parathyroid glands and a number of parathyroid transplantation procedures. The endoscopic group was treated during an earlier stage of thyroid cancer. The iPTH profile of each group decreased, although this was the most consistent in the OTA-H group. A comparison of ETBAA with OTA-L demonstrates that the iPTH level change is similar.
\end{abstract}

Conclusion: There is no advantage of endoscopic treatment for preserving parathyroid function.

Keywords: Thyroid surgery, Hypocalcemia, Intact PTH (iPTH), Central compartment lymph node dissection, Morbidity

\section{Background}

The prevalence of hypocalcemia following thyroidectomy and central compartment lymph node dissection (CND) for papillary thyroid cancer (PTC) is high, with overall rates of $25 \%$ transient and $3 \%$ permanent [1]. This may be a result of manipulation of the parathyroid

\footnotetext{
*Correspondence: liangnan2006@163.com; thyroidj|@163.com

${ }^{\dagger}$ Nan Liang and Hui Sun contributed equally to this work.

${ }^{1}$ Department of Thyroid Surgery, China-Japan Union Hospital Of Jilin

University, Jilin Provincial Key Laboratory Of Surgical Translational Medicine,

Jilin Provincial Precision Medicine Laboratory of Molecular Biology and

Translational Medicine on Differentiated Thyroid Carcinoma, 126 Xiantai Blvd,

Changchun city, Jilin province, People's Republic of China

Full list of author information is available at the end of the article
}

gland or devascularization, or may be caused by inadvertent removal along with the thyroid specimen [2-7].

Biochemical studies of post-thyroidectomy patients have shown that intact parathyroid hormone (iPTH) sampling is a valid, early predictor of the postoperative parathyroid gland state [1]. Limited data is available for assessing the state of the parathyroid following CND in endoscopic thyroidectomy [1-11].

This study aims to compare the kinetics of $\mathrm{iPTH}$ in the perioperative period of endoscopic thyroidectomy via bilateral areola approach (ETBAA) with the same period following a traditional open thyroidectomy approach (OTA).

(c) The Author(s). 2019 Open Access This article is distributed under the terms of the Creative Commons Attribution 4.0 International License (http://creativecommons.org/licenses/by/4.0/), which permits unrestricted use, distribution, and reproduction in any medium, provided you give appropriate credit to the original author(s) and the source, provide a link to the Creative Commons license, and indicate if changes were made. The Creative Commons Public Domain Dedication waiver (http://creativecommons.org/publicdomain/zero/1.0/) applies to the data made available in this article, unless otherwise stated. 


\section{Methods}

\section{Study design}

Patients who had undergone total thyroidectomy and CND for thyroid cancer with postoperative iPTH evaluation were prospectively observed between October 2013 and April 2018. All participants gave informed consent before research commenced. The study was conducted in accordance with the Declaration of Helsinki, while the protocol was approved by the ethics committee of China-Japan Union Hospital of Jilin University (see protocol n. 2012-wjw-004).

\section{Setting}

Research took place at the Academic Hospital, which is a single institutional, tertiary referral center.

\section{Participants}

Patients who had undergone thyroidectomy without CND, concomitant parathyroid disease, renal failure, unilateral lobectomy, 'berry picking' dissection, re-done central neck dissections, high or low basal iPTH values (normal range 15-65 pg/ml) were excluded from analysis. Patients with vitamin D deficiency or preoperative calcium supplementation were also excluded. Inclusion and exclusion criteria for ETBAA can be seen in Table 1. The study only included patients with a malignant thyroid disease. Cancer patients were placed into three

Table 1 Detailed inclusion and exclusion criteria for ETBAA

\begin{tabular}{l} 
Selection and Exclusion criteria \\
\hline Selection criteria \\
Papillary thyroid cancer with low-risk factors ${ }^{\mathrm{a}}$ \\
Dominant benign nodule with a diameter $<5 \mathrm{~cm}$, whereas cystic \\
nodule could be $6 \mathrm{~cm}$ or greater \\
The patients needed a cosmetic requirement \\
Exclusion criteria \\
General factors \\
Obesity and stocky neck \\
Clinical history of radiation or surgery on the neck or chest \\
Preoperative dysfunction of voice cord \\
Thyroid-related factors \\
Advanced cancer \\
Local invasion \\
Posteriorly located lesions \\
Diffuse or adhesion or fixation enlargement of lymph node \\
Evidence available of local or distant metastases \\
Graves' disease \\
Severe thyroiditis \\
Associated parathyroid disease
\end{tabular}

${ }^{a}$ Low risk factors including lesion size $<4 \mathrm{~cm}$, age $<55$ years, no prior radiation, no distant metastases, no lymph node metastases, no extrathyroidal extension, no aggressive variant, and no first-degree family history of thyroid carcinoma groups: (A) patients who were eligible for endoscopic treatment and who accepted ETBAA (ETBAA); (B) patients eligible for ETBAA yet who opted for OTA (OTA-L); (C) those cancer patients who were ineligible for endoscopic intervention who had undergone OTA (OTA-H). The inclusion criterion was $\mathrm{cNO}$ on clinical and US examination for the ETBAA and OTA-L group, while those from the OTA-H group were ineligible for endoscopic intervention, including cN1. See Fig. 1 for a grouping flow chart. Patients could be included if they had PTC, been diagnosed preoperatively using cytological diagnosis, were diagnosed with N0 neck either clinically or following ultrasonography (US), and those whose diagnosis had been confirmed following intraoperative inspection.

\section{Definitions and interventions}

All participants were subjected to preoperative highresolution US [12]. The 2009 Bethesda classification system of thyroid cytopathology was utilized [12]. Noncontrast slides from CT scans were frequently utilized during the initial evaluation of a solitary thyroid cancer.

\section{Surgical technique}

The ETBAA technique has been previously described (Additional file 1: Video S1) [13]. The third and fourth intercostal incisions of male ETBAA patients are conventionally used for the endoscopic access. The middle incision is $12 \mathrm{~mm}$, and the bilateral incisions are approximately 5-6 $\mathrm{mm}$. The central neck dissection (level VI) is then performed similarly to that of women patients. Standardized neural monitoring was implemented in all groups [13]. All surgeries were performed by the same endocrine surgeon (DZ). Dissection and hemostasis were achieved in OTA with a Focus Plus device, and were achieved in ETBAA by means of an ACE plus device (Johnson \& Johnson Company, Cincinnati, OH, USA). Drainage tubes were attached from the chest incision.

\section{Parathyroid gland scheme location and dissection}

Preservation of the parathyroid glands as well as their blood supply was attempted in all cases. Efforts to identify all four glands also took place in all cases. However, an extensive neck exploration to search for one or two missing glands was not carried out. A classification scheme for parathyroid glands location was utilized (see Fig. 2). Type A: the gland is firmly fixed to thyroid gland. Type A can be grouped into three subtypes. A1: the parathyroid gland is attached to the inherent thyroid capsule. A2: the gland is partially embedded in thyroid gland. A3: the gland is located in thyroid tissue and is discovered after thyroid gland excision. Type B can be 

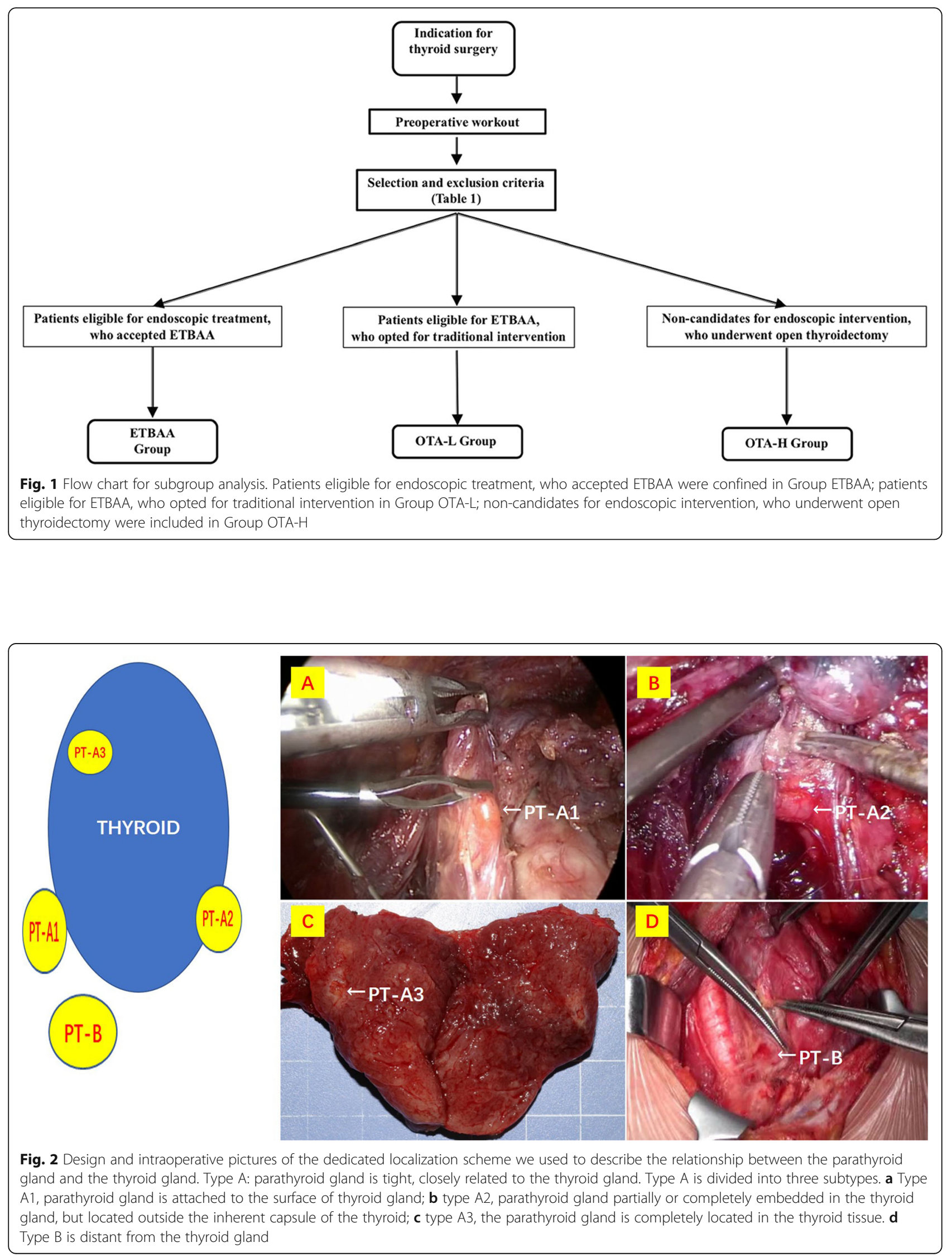
defined as a gland which is separate from the thyroid gland [14].

\section{Parathyroid autotransplantation}

In cases where the parathyroid glands had been damaged, auto-transplantation was undertaken. Prior to auto-transplantation, a section of a fragment of the parathyroid gland was frozen. Parathyroid tissue was stored in a saline solution after excision. Sliced parathyroid tissue and $1 \mathrm{ml}$ of saline was withdrawn into a syringe and injected into the monolateral sternocleidomastoid muscle (Additional file 1: Video S1).

\section{Technique for CND}

The techniques for CND applied have been described previously $[8,15-17]$.

\section{iPTH and calcium determinations}

iPTH measurements were assessed by chemiluminescence (STAT-Intraoperative-Intact-PTH, Future Diagnostics, Wijchen, Netherlands). Venous samples were obtained before surgery and at skin closure. According to our proto$\mathrm{col}$, if iPTH was $<15 \mathrm{pg} / \mathrm{mL}$, then the subject received oral calcium and vitamin D substitution [15-17]. Serum calcium (range 2.2 to $2.6 \mathrm{mmol} / \mathrm{L}$ ) was monitored at 24 , $48,72 \mathrm{~h}$ and +15 days postoperatively. On follow-up visits at $+1,3$ and 6 months, both the serum calcium and the iPTH level were verified [15-17]. If two consecutive serum calcium determinations were within or above the normal value, then firstly calcium and secondly vitamin D were no longer given [15-17].

\section{Follow-up}

Pre- and postoperative follow-up included laryngoscopy [15-17]. Measurement of serum Thyroglobulin, stimulated thyroglobulin hormone (TSH) and thyroglobulin antibodies were monitored in all patients after surgery in the follow up period [15-17]. After surgery, patients were given TSH-suppressive L-thyroxine therapy [12]. The seventh edition of the AJCC/TNM cancer staging system was used [12]. Papillary thyroid cancer indications for RAI treatment (4-5 weeks after surgery) include: $>45$ years or $<18$ years; tumor $>2 \mathrm{~cm}$; thyroid capsule, soft tissue, adjacent organ tumor extension; $\mathrm{LN}+$ (in any area of the neck); non-classical variants of PTC; M+; remnant ablation; BRAF+.

Neither profiles of thyroglobulin, TSH and thyroglobulin antibodies nor prevalence/dose of RAI analysis are the purpose of this preliminary report.

\section{Primary outcome}

iPTH kinetics in ETBAA versus open surgery were considered as the primary end-point.

\section{Statistics}

$\mathrm{PTH}<15 \mathrm{pg} / \mathrm{ml}$ was utilized for statistical testing [15-17]. The cut-off value for the serum calcium level was $2.0 \mathrm{mmol} / \mathrm{L}$ [7, 15-17]. Analysis of the data was calculated using SPSS version 19.0 (SPSS Inc., Chicago, USA) and SAS version 9.4 (SAS Inc., North Carolina, USA). Data were presented as mean \pm standard deviation. The differences between parathyroid gland outcomes, changes of PTH perioperative or serum calcium and calcium supplementation in the ETBAA, OTA-L and OTA-H groups were analyzed using Cochran's and Mantel-Haenszel Chi-square test. The level of statistical significant was 0.05 .

\section{Results}

Data collection analysis

Over the six-year period of the study, 315 patients underwent total thyroidectomy and CND as a one-stage procedure. Figure 3 depicts a flow chart with the number of patients eligible and not eligible for the study.

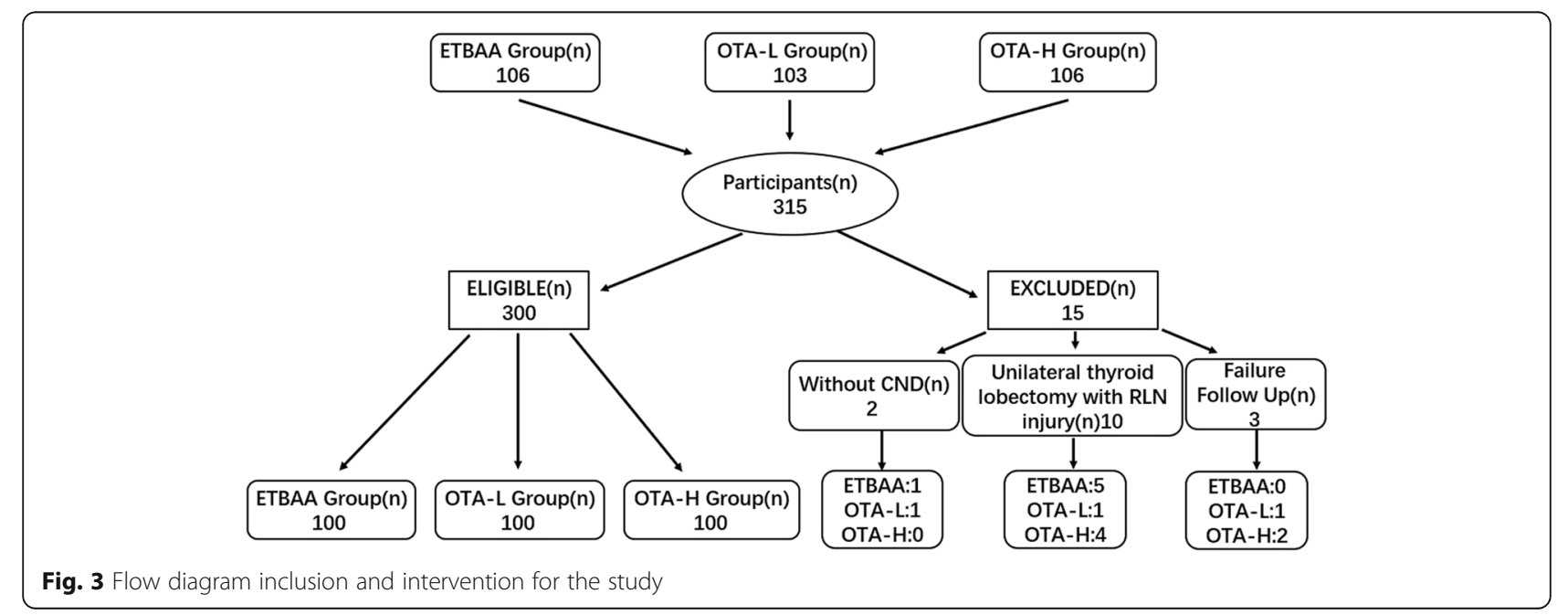


Based on the selection and exclusion criteria, 300 patients were eligible for the study. These were 44 men and 256 women, aged 16-54 years (median 37.7). Demographic, clinical, laboratory, operative, morbidity and histology data can been seen in Table 2. Mean length of follow-up was $20 \pm 6$ months (range five to 52 months). No instances of instrument malfunction (neuromonitoring, endoscopy, ultrasound scalpel and so on) were recorded in this study.

\section{Comparative study}

There were 100 patients in each group. In the ETBAA group, mean age was $31.2 \pm 9.31$, and there were 11 male and 89 female participants. In the OTA-L group, mean age was $36.2 \pm 10.5$, and there were 16 male and 84 female patients. In the OTA-H group, mean age was
$47.9 \pm 15.7$, while there were 17 male and 83 female participants. The only significant difference between the ETBAA and OTA-L groups was the mean operating time and drainage (Table 2). The preoperative TSH $(P=$ $0.17)$ and tireoglobulin levels $(P=0.26)$ were seen to be within the normal range for both groups. None of the patients in the study population had a preoperative recurrent laryngeal nerve (RLN) palsy. There was no significant difference found between the incidence of hypoparathyroidism (permanent $0 \%$ versus $1 \%$; transient $7 \%$ versus $5 \%$ ) and hypocalcemia (permanent $0 \%$ versus $1 \%$; transient $9 \%$ versus $10 \%$ ) (Table 2 ). A comparison of the ETBAA and OTA-H groups and of the OTA-L and OTA-H groups found that the mean tumor diameter, rate of extracapsular invasion and number of lymph node metastases were significantly different and were

Table 2 Patients characteristics

\begin{tabular}{|c|c|c|c|}
\hline & $\begin{array}{l}\text { ETBAA } \\
(N=100)\end{array}$ & $\begin{array}{l}\text { OTA-L } \\
(N=100)\end{array}$ & $\begin{array}{l}\text { OTA-H } \\
(N=100)\end{array}$ \\
\hline Age $\pm S D$ (years) & $31.2 \pm 9.31$ & $36.2 \pm 10.5$ & $47.9 \pm 15.7$ \\
\hline Gender (M/F) & $11 / 89$ & $16 / 84$ & $17 / 83$ \\
\hline \multicolumn{4}{|l|}{ Central lymph node dissection } \\
\hline Prophylactic & 100 & 100 & 17 \\
\hline Therapeutic & 0 & 0 & 83 \\
\hline Mean operating time (min) & $124.8 \pm 19.4$ & $43.8 \pm 9.29$ & $57.9 \pm 12.23$ \\
\hline intraoperative blood loss (ml) & $7.02 \pm 3.44$ & $6.56 \pm 3.24$ & $8.31 \pm 3.15$ \\
\hline Postoperative hospital stay time(D) & $3.88 \pm 0.52$ & $3.13 \pm 0.76$ & $4.02 \pm 0.98$ \\
\hline Total drain volumes (ml) & $63.34 \pm 21.2$ & $25.18 \pm 18.3$ & $52.28 \pm 16.9$ \\
\hline Mean draining days & $1.85 \pm 0.42$ & $1.39 \pm 0.37$ & $1.89 \pm 0.62$ \\
\hline Parathyroid dysfunction (number) & 7 & 6 & 15 \\
\hline Transient & 7 & 5 & 12 \\
\hline Persistent & 0 & 1 & 3 \\
\hline Hypocalcemia (number) & 9 & 11 & 18 \\
\hline Transient & 9 & 10 & 15 \\
\hline Persistent & 0 & 1 & 3 \\
\hline Recurrent laryngeal injury (number) & 7 & 2 & 6 \\
\hline Transient & 7 & 2 & 4 \\
\hline Definitive & 0 & 0 & 2 \\
\hline \multicolumn{4}{|l|}{ Histopathology } \\
\hline papillary thyroid carcinoma & 100 & 100 & 100 \\
\hline Thyroid volume $\left(\mathrm{mm}^{3}\right)$ & $7445 \pm 438$ & $7562 \pm 492$ & $8250 \pm 509$ \\
\hline Mean diameter of tumor (cm) & $0.89 \pm 0.52$ & $0.93 \pm 0.43$ & $2.85 \pm 1.83$ \\
\hline Extracapsular invasion(+/total) & $0 / 100$ & $0 / 100$ & $43 / 100$ \\
\hline Parathyroid in specimen & 4 & 3 & 7 \\
\hline Coexistence thyroiditis & 9 & 11 & 22 \\
\hline Mean number of LN(n) & $7.78 \pm 2.03$ & $2.99 \pm 1.53$ & $10.3 \pm 3.4$ \\
\hline Mean Metastatic (n) & $2.17 \pm 3.12$ & $0.77 \pm 1.29$ & $3.47 \pm 4.08$ \\
\hline
\end{tabular}

$\mathrm{N}$ is the number of patients in the different groups

Data, which fitted the normal distribution, were presented as Mean \pm SD 
positively correlated with both hypoparathyroidism and hypocalcemia following surgery (Table 2). The endoscopic group were treated during an earlier stage of thyroid cancer. Regarding RLN injury, both transient and permanent unilateral palsy were found in the ETBAA group at 7\% versus $0 \%$, the OTA- $\mathrm{H}$ group at $4 \%$ versus $2 \%$ and the OTA-L group at $2 \%$ versus $0 \%(p>0.05)$ (Table 2). No cases of bilateral palsy were found.

\section{Parathyroid gland identification, position and transplantation}

A significant difference was found between the ETBAA and OTA-H groups in parathyroid type A2, as well as a loss of parathyroid glands and a number of parathyroid transplantation procedures $(P<0.05)$. Details are described in Table 3 and Fig. 4.

\section{iPTH profile}

No significant difference was found in preoperative iPTH values between the OTA-L, OTA-H and ETBAA groups (Table 4, Fig. 5). Fifteen minutes following surgery, the iPTH profile of each group decreased, although this was most consistent in the OTA-H group (Fig. 5). No significant difference was found in $\mathrm{PTTH}$ between the ETBAA and OTA-L groups. There was a significant difference found between the OTA-H and ETBAA groups, and between the OTA-H and OTA-L groups (Table 4). When comparing the ETBAA with OTA-L, the $\mathrm{iPTH}$ level change is similar.

\section{Serum $\mathrm{Ca}$ and supplementation}

No significant difference was found in basal serum Ca values for the OTA-L, OTA-H and ETBAA groups (Fig. 6, Table 5). On the first day following surgery, there was no significant difference found in serum $\mathrm{Ca}$ values between the OTA-L, OTA-H and ETBAA groups. No significant difference was found in calcium supplementation between the OTA-L and ETBAA groups.

On day two after surgery, no difference was found in the serum $\mathrm{Ca}$ values of the OTA-L and ETBAA groups. However, a significant difference was discovered in serum $\mathrm{Ca}$ values between the OTA-H and ETBAA groups, as well as the OTA-H and OTA-L groups. There was also a difference in calcium supplementation between OTA-H and ETBAA groups as well as the OTA$\mathrm{H}$ and OTA-L groups.

On the third day after surgery, no significant difference was found in the serum $\mathrm{Ca}$ values between the OTA-L, OTA-H and ETBAA groups. Statistical analysis found a positive correlation in calcium supplementation between the OTA-H and ETBAA groups as well as between the OTA-H and OTA-L groups (Table 5, Fig. 6).
Table 3 Parathyroid glands outcomes

\begin{tabular}{|c|c|c|c|}
\hline & ETBAA & OTA-L & OTA-H \\
\hline \multicolumn{4}{|c|}{ Number of glands identified } \\
\hline 1 & 0 & 0 & 1 \\
\hline 2 & 3 & 4 & 5 \\
\hline 3 & 6 & 8 & 6 \\
\hline 4 & 91 & 88 & 88 \\
\hline Total & 388 & 384 & 381 \\
\hline \multicolumn{4}{|c|}{ Location of glands identified } \\
\hline Superior & $200 / 200^{* *}$ & $197 / 200$ & $194 / 200$ \# \\
\hline Inferior & $188 / 200$ & $187 / 200$ & $187 / 200$ \\
\hline Right side & $191 / 200$ & $191 / 200$ & $192 / 200$ \\
\hline Left side & $197 / 200^{*}$ & 193/200 & $189 / 200^{\#}$ \\
\hline Superior right & $100 / 100$ & $99 / 100$ & $98 / 100$ \\
\hline Superior left & $100 / 100^{*}$ & $98 / 100$ & $96 / 100^{\#}$ \\
\hline Inferior right & $91 / 100$ & $92 / 100$ & $94 / 100$ \\
\hline Inferior left & $97 / 100$ & $95 / 100$ & $93 / 100$ \\
\hline \multicolumn{4}{|c|}{ Parathyroid gland scheme } \\
\hline Type A & $358 / 388$ & $363 / 384$ & $351 / 381$ \\
\hline $\mathrm{A} 1$ & $284 / 388$ & $275 / 384$ & $256 / 381$ \\
\hline$A 2$ & $73 / 388^{*}$ & $86 / 384$ & $92 / 381^{\#}$ \\
\hline A3 & $1 / 388$ & $2 / 384$ & $3 / 381$ \\
\hline Type B & $30 / 388$ & $21 / 384$ & $30 / 381$ \\
\hline \multicolumn{4}{|c|}{ Incidental parathyroidectomy } \\
\hline \multicolumn{4}{|c|}{ Location of removed } \\
\hline Intrathyroidal & $1 / 388$ & $2 / 384$ & $3 / 381$ \\
\hline Subcapsular & $6 / 388$ & $9 / 384$ & $12 / 381$ \\
\hline Extracapsular & $0 / 388^{* *}$ & $3 / 384$ & $7 / 381^{\#}$ \\
\hline \multicolumn{4}{|l|}{ Number of removed } \\
\hline 1 & $7 / 388$ & $9 / 384$ & $15 / 381$ \\
\hline 2 & $0 / 388^{*}$ & $1 / 384$ & $2 / 381^{\#}$ \\
\hline 3 & $0 / 388$ & $1 / 384$ & $1 / 381$ \\
\hline Fragment & $0 / 388$ & $0 / 384$ & $0 / 381$ \\
\hline Auto-transplantation & $7 / 388^{* *}$ & $14 / 384$ & $22 / 381^{\#}$ \\
\hline
\end{tabular}

${ }^{*} P<0.05,{ }^{* *} P<0.01$; analysis of the total three groups with Cochran's and Mantel-Haenszel Chi-square $\left(\mathrm{XCMH}^{2}\right)$ test, while the variable of side was controlled

${ }^{\#} P<\alpha^{\prime}$, analysis of group ETBAA and group OTA-H with $\mathrm{XCMH} 2$ test, $a^{\prime}=a / 4=0.0125$

\section{Histopathology}

Histopathology confirmed that all participants had suffered from PTC. There was a significant difference found in thyroid volume, mean diameter of tumor, extracapsular invasion, coexistence thyroiditis and level VI metastasis between the OTA-H and ETBAA groups as well as between the OTA-H and OTA-L groups (Table 2). A significant difference was found in the mean number of lymph nodes dissected between the OTA-L and ETBAA groups as well as the OTA-L and OTA-H groups 


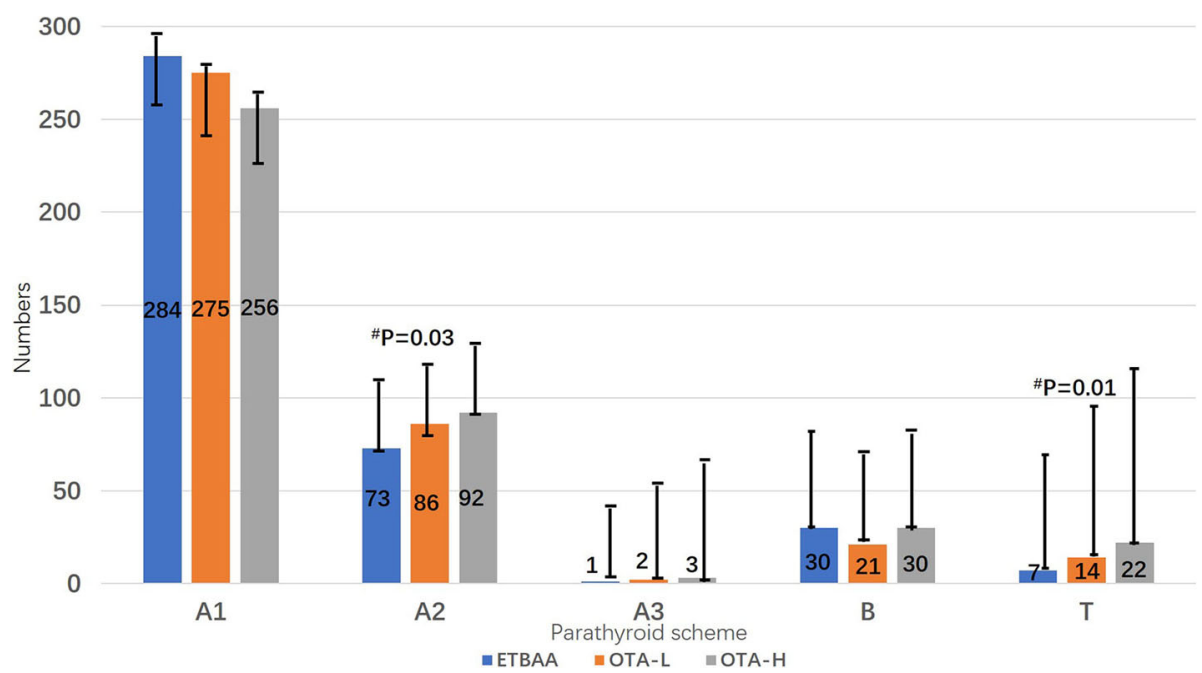

Fig. 4 Comparative analysis for parathyroid location and strategy. A1, parathyroid gland is attached to the surface of thyroid gland; A2, parathyroid gland partially or completely embedded in the thyroid gland, but located outside the inherent capsule of the thyroid; $A 3$, the parathyroid gland is completely located in the thyroid tissue. B is distant from the thyroid gland, which is easier to preserve in situ. T, Intraoperative auto-transplantation of parathyroid gland. " $\mathrm{P}$, Comparisons of groups between ETBAA and OTA-H

(Table 2). Statistics found a positive correlation in the mean number of metastasis between the OTA-L and ETBAA groups as well as the OTA-L and OTA-H groups.

\section{Discussion}

We described parathyroid gland-related kinetics in the context of the current practices of both OTA and ETBAA. In this prospective observational study, $300 \mathrm{pa}-$ tients who had undergone thyroidectomy and central neck dissection were reviewed. Patients were stratified into three groups: those eligible for endoscopic treatment (ETBAA); patients who were eligible for ETBAA and had opted for OTA (OTA-L); and patients who were not suitable for endoscopic intervention (OTA-H). iPTH measurements for each patient were taken at preestablished points during the periods before and after surgery.

The iPTH profile of each group decreased, although this was the most consistent in the OTA-H group. When comparing the ETBAA with OTA-L, the iPTH level change is similar. Therefore, we can conclude that there is no advantage to using endoscopic treatment to preserve parathyroid function.
Thyroidectomy and CND are starting to be included in international guidelines $[8,12]$. There is, therefore, an increased interest in the precise description of morbidity related to the procedures. Parathyroid gland preservation is recommended during ETBAA, as are other endocrine endoscopic and open techniques [15-17]. The dearth of studies which address the kinetics of iPTH during ETBAA led us to investigate hormone profile in comparison to well-standardized procedures such as OTA. We hypothesized that differences in iPTH kinetics may result in different thyroid gland approaches [15-17]. This is the first study to analyze the iPTH profile in ETBAA.

No other studies have compared the kinetics of iPTH levels after thyroidectomy and CND in ETBAA versus open surgery. Our study clarifies the kinetics of iPTH following 300 thyroidectomy and lymph node clearance procedures. The results of this study suggest the relevance of perioperative iPTH decline in CND for both open and endoscopic procedures. We have described a decrease between preoperative iPTH levels which is significantly related to the number of lymph nodes dissected, their metastatic status, and the type of parathyroid gland location.

Table 4 Changes of PTH before and after operation

\begin{tabular}{lll}
\hline & ETBAA & OTA-L \\
\hline Preoperative $(\mathrm{pg} / \mathrm{mL})$ & $49.18 \pm 23.18$ & $52.49 \pm 20.34$ \\
15 min postoperative $(\mathrm{pg} / \mathrm{mL})$ & $30.84 \pm 17.55^{* *}$ & $31.27 \pm 22.66^{ \pm}$ \\
\hline
\end{tabular}

${ }^{*} P<0.05,{ }^{* *} P<0.01$; analysis of the total three groups with Cochran's and Mantel-Haenszel Chi-square $\left(\mathrm{X}_{\mathrm{CMH}}{ }^{2}\right)$ test, while the variable of side was controlled ${ }^{\#} P<\alpha^{\prime}$, analysis of group ETBAA and group OTA-H with $X_{\mathrm{CMH}}{ }^{2}$ test, $\alpha^{\prime}=\alpha / 4=0.0125$

${ }^{\mathrm{E}} P<\mathrm{a}^{\prime}$, analysis of group OTA-L and group OTA-H with $X_{\mathrm{CMH}}{ }^{2}$ test, $a^{\prime}=\alpha / 4=0.0125$ 


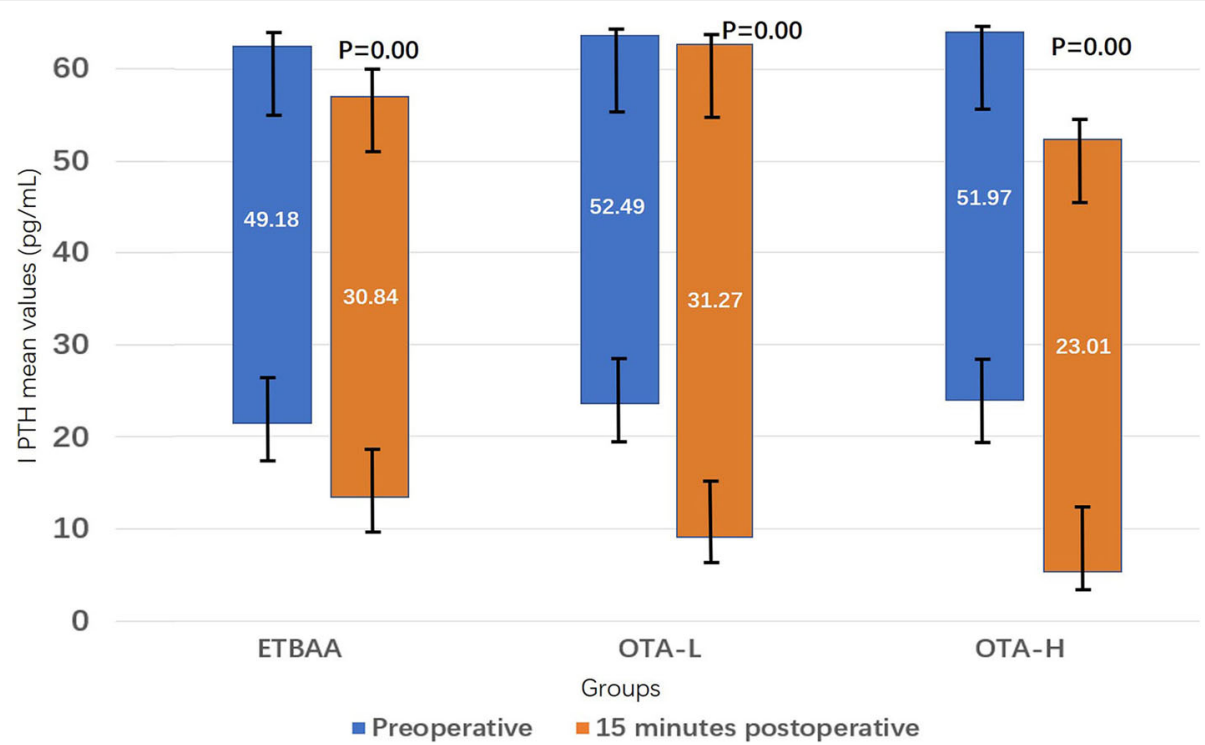

Fig. 5 iPTH kinetics. P, Comparisons of Preoperative and $15 \mathrm{~min}$ postoperative in each group

Fifteen minutes after surgery, the iPTH profile of each group had decreased, although this was most consistent in the OTA-H group. No significant difference was found in iPTH between the ETBAA and OTA-L groups following surgery. However, there was a significant difference between the OTA-H and ETBAA groups as well as between the OTA-H and OTA-L groups. Perhaps the endoscopic magnification of the parathyroid glands during ETBAA has the potential to enhance gland preservation [15-17].

There are limitations to the present study. It is important to identify factors that cause interpatient variability

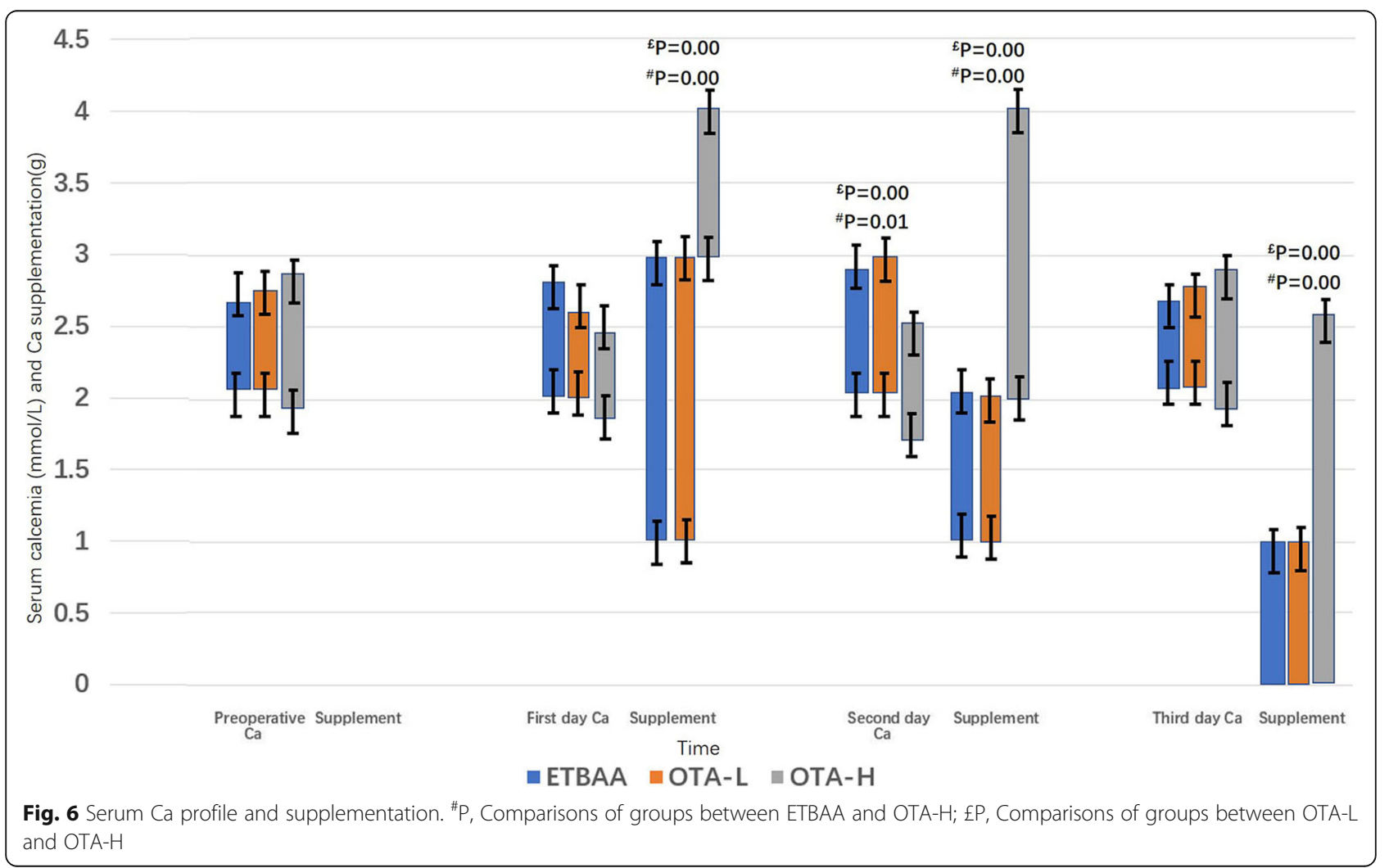


Table 5 Serum calcium and calcium supplementation

\begin{tabular}{|c|c|c|c|}
\hline & ETBAA & OTA-L & OTA-H \\
\hline \multicolumn{4}{|l|}{ Preoperative } \\
\hline Calcium (mmol/L) & $2.32 \pm 0.21$ & $2.33 \pm 0.19$ & $2.29 \pm 0.39$ \\
\hline Supplementation (g) & 0 & 0 & 0 \\
\hline \multicolumn{4}{|l|}{ First day postoperation } \\
\hline Calcium (mmol/L) & $2.28 \pm 0.32$ & $2.35 \pm 0.22$ & $2.13 \pm 0.37$ \\
\hline Supplementation (g) & $2.56 \pm 0.48^{* *}$ & $2.59 \pm 0.32^{£}$ & $3.82 \pm 0.46^{\#}$ \\
\hline \multicolumn{4}{|c|}{ second day postoperation } \\
\hline Calcium (mmol/L) & $2.21 \pm 0.37^{* *}$ & $2.27 \pm 0.31^{ \pm}$ & $2.09 \pm 0.41^{\#}$ \\
\hline Supplementation (g) & $1.89 \pm 0.32^{* *}$ & $1.93 \pm 0.26^{ \pm}$ & $2.75 \pm 0.41^{\#}$ \\
\hline \multicolumn{4}{|l|}{ third day postoperation } \\
\hline Calcium (mmol/L) & $2.25 \pm 0.18$ & $2.26 \pm 0.19$ & $2.18 \pm 0.39$ \\
\hline Supplementation (g) & $0.52 \pm 0.61^{* *}$ & $0.41 \pm 0.61^{ \pm}$ & $1.83 \pm 0.37^{\#}$ \\
\hline
\end{tabular}

${ }^{*} P<0.05$, ${ }^{* *} P<0.01$; analysis of the total three groups with Cochran's and Mantel-Haenszel Chi-square $\left(\mathrm{XсMH}^{2}\right)$ test, while the variable of side was controlled

${ }^{\#} P<\alpha^{\prime}$, analysis of group ETBAA and group OTA-H with $\mathrm{XCMH}^{2}$ test, $a^{\prime}=a / 4=0.0125$

${ }^{\mathrm{E}} P<\mathrm{a}^{\prime}$, analysis of group OTA-L and group OTA-H with $\mathrm{X}_{\mathrm{CMH}}{ }^{2}$

test, $a^{\prime}=a / 4=0.0125$

in $\mathrm{iPTH}$ responses. A significant difference was found between ETBAA and OTA-H groups in parathyroid type A2, as well as a loss of parathyroid glands and a number of parathyroid transplantation procedures (Table 3 and Fig. 4). The significant differences we found may also be due to the selection of participants. Patients who are eligible for endoscopic surgery have less extensive disease and improved general factors when compared to other patients (Table 1). This has the potential to contribute to a more difficult surgery in the open surgery group, which can in turn necessitate and lead to more extensive preparations during surgery, which then obviously increase the risk of damage to the parathyroid glands.

\section{Conclusion}

Patients with PTC were stratified into three groups: those eligible for ETBAA; those who were eligible for ETBAA yet opted for OTA (OTA-L); and those who were not suitable for endoscopic approach (OTA-H). The postoperative iPTH profile of each group decreased, although this was most consistent in OTA-H group. When comparing ETBAA and OTA-L, iPTH level profiles were similar. Thus, there is no advantage of endoscopic treatment over open surgery for preserving parathyroid function.

\section{Supplementary information}

Supplementary information accompanies this paper at https://doi.org/10. 1186/s12893-019-0656-8

Additional file 1: Video S1. The procedure of protection and autotransplantation of parathyroid gland in ETBAA and open thyroid surgery. The video show that the ETBAA and open thyroid surgery should be carefully operated to protect parathyroid gland and its blood supply in situ as far as possible. The parathyroid gland with poor blood supply should be transplanted into sternocleidomastoid muscle in time.

\section{Abbreviations}

CND: Central compartment lymph node dissection; ETBAA: Endoscopic thyroidectomy via bilateral areola approach; iPTH: Intact parathyroid hormone; OTA: Open thyroidectomy approach; OTA-H: Ineligible for endoscopic intervention who had undergone OTA; OTA-L: Patients eligible for ETBAA yet who opted for OTA; PTC: Papillary thyroid cancer;

TSH: Stimulated thyroglobulin hormone; US: Ultrasonography

\section{Acknowledgements}

Not applicable.

\section{Authors' contributions}

Conception and design: HS, NL and GD; Administrative support: HS, NL and GD; Collection and assembly of data: DQZ; Data analysis and interpretation: All authors; Manuscript writing: All authors; Final approval of manuscript: All authors.

\section{Funding}

This study was funded by The National Nature Science Foundation of China (no. 81702651), China Postdoctoral Science Foundation (no. 2017 M611313), Department of Science and Technology of Jilin Province (no. 20170520018J H and $20190201225 \mathrm{JC})$. These Funding provide financial support for this study, in the design of the study and collection, analysis, and interpretation of data and in writing the manuscript.

\section{Availability of data and materials}

The datasets generated and/or analyzed during the current study are not publicly available due to protecting individual patient privacy but are available from the corresponding author on reasonable request.

\section{Ethics approval and consent to participate}

All procedures performed in studies involving human participants were in accordance with the 1964 Helsinki declaration and its later amendments or comparable ethical standards, while the protocol was approved by the ethics committee of China-Japan Union Hospital of Jilin University (see protocol n. 2012-wjw-004). Informed consent of written was obtained from all individual participants included in the study.

Consent for publication

Not applicable.

\section{Competing interests}

The authors declare that they have no competing interests.

\section{Author details}

'Department of Thyroid Surgery, China-Japan Union Hospital Of Jilin University, Jilin Provincial Key Laboratory Of Surgical Translational Medicine, Jilin Provincial Precision Medicine Laboratory of Molecular Biology and Translational Medicine on Differentiated Thyroid Carcinoma, 126 Xiantai Blvd, Changchun city, Jilin province, People's Republic of China. ${ }^{2}$ Division for Endocrine and Minimally Invasive Surgery, Department of Human Pathology in Adulthood and Childhood "G. Barresi", University Hospital G. Martino, University of Messina, Via C. Valeria 1, 98125 Messina, Italy.

Received: 28 March 2019 Accepted: 27 November 2019

Published online: 11 December 2019

\section{References}

1. Julián MT, Balibrea JM, Granada ML, Moreno P, Alastrué A, Puig-Domingo M, Lucas A. Intact parathyroid hormone measurement at 24 hours after thyroid surgery as predictor of parathyroid function at long term. Am J Surg. 2013; 206(5):783-9. https://doi.org/10.1016/j.amjsurg.2013.01.038 Epub 2013 Jul 5. PubMed PMID: 23835208.2

2. Noordzij JP, Lee SL, Bernet VJ, Payne RJ, Cohen SM, McLeod IK, Hier MP, Black MJ, Kerr PD, Richards ML, Lo CY, Raffaelli M, Bellantone R, Lombardi 
CP, Cohen Jl, Dietrich MS. Early prediction of hypocalcemia after thyroidectomy using parathyroid hormone: an analysis of pooled individual patient data from nine observational studies. J Am Coll Surg. 2007;205(6): 748-54 Epub 2007 Sep 18. PubMed PMID: 18035257.

3. Payne RJ, Hier MP, Tamilia M, Young J, MacNamara E, Black MJ. Postoperative parathyroid hormone level as a predictor of postthyroidectomy hypocalcemia. J Otolaryngol. 2003;32(6):362-7 PubMed PMID: 14967080.

4. Payne RJ, Tewfik MA, Hier MP, Tamilia M, Mac Namara E, Young J, Black MJ. Benefits resulting from 1- and 6-hour parathyroid hormone and calcium levels after thyroidectomy. Otolaryngol Head Neck Surg. 2005;133(3):386-90 PubMed PMID: 16143187.

5. Payne RJ, Hier MP, Côté V, Tamilia M, MacNamara E, Black MJ. Postoperative parathyroid hormone levels in conjunction with corrected calcium values as a predictor of post-thyroidectomy hypocalcemia: review of outcomes 1 year after the implementation of a new protocol. J Otolaryngol. 2005;34(5):323-7 PubMed PMID: 16181594.6.

6. Graciano AJ, Chone CT, Fischer CA. Applicability of immediate, late or serial intact parathyroid hormone measurement following total thyroidectomy. Braz J Otorhinolaryngol. 2012;78:78-82. https://doi.org/10.5935/1808-8694. 20120012.

7. Yano Y, Masaki C, Sugino K, Nagahama M, Kitagawa W, Sibuya H, Ito K. Serum intact parathyroid hormone level after total thyroidectomy or total thyroidectomy plus lymph node dissection for thyroid nodules: report from 296 surgical cases. Int J Endocrinol Metab. 2012;10(4):594-8. https://doi.org/ 10.5812/ijem.3462 Epub 2012 Sep 30. PubMed PMID: 23843829; PubMed Central PMCID: PMC36936438.

8. American Thyroid Association Surgery Working Group, American Association of Endocrine Surgeons, American Academy of Otolaryngology- Head and Neck Surgery, et al. Consensus statement on the terminology and classification of central neck dissection for thyroid cancer. Thyroid. 2009; 19(11):1153-8.

9. Vanderlei FA, Vieira JG, Hojaij FC, Cervantes O, Kunii IS, Ohe MN, Santos RO, Abrahão M. Parathyroid hormone: an early predictor of symptomatic hypocalcemia after total thyroidectomy. Arq Bras Endocrinol Metabol. 2012; 56(3):168-72 PubMed PMID: 22666731.10.

10. Kim JP, Park JJ, Son HY, Kim RB, Kim HY, Woo SH. Effectiveness of an i-PTH measurement in predicting post thyroidectomy hypocalcemia: prospective controlled study. Yonsei Med J. 2013;54(3):637-42. https://doi.org/10.3349/ ymj.2013.54.3.637 PubMed PMID: 23549808; PubMed Central PMCID: PMC3635650.

11. Lang BH, Yih PC, Ng KK. A prospective evaluation of quick intraoperative parathyroid hormone assay at the time of skin closure in predicting clinically relevant hypocalcemia after thyroidectomy. World J Surg. 2012;36: 1300-6. https://doi.org/10.1007/s00268-012-1561-9.

12. Haugen BR, Alexander EK, Bible KC, Doherty GM, Mandel SJ, Nikiforov YE, Pacini F, Randolph GW, Sawka AM, Schlumberger M, Schuff KG, Sherman SI, Sosa JA, Steward DL, Tuttle RM, Wartofsky L. 2015 American Thyroid Association Management Guidelines for Adult Patients with Thyroid Nodules and Differentiated Thyroid Cancer: The American Thyroid Association Guidelines Task Force on Thyroid Nodules and Differentiated Thyroid Cancer. Thyroid. 2016;26(1):1-133. https://doi.org/10.1089/thy.2015. 0020 Review. PubMed PMID: 26462967; PubMed Central PMCID: PMC4739132.

13. Zhang D, Fu Q, Dionigi G, Wang T, Xin J, Zhang J, Xue G, Li H, Sun H. Intraoperative Neural Monitoring in Endoscopic Thyroidectomy Via Bilateral Areola Approach. Surg Laparosc Endosc Percutan Tech. 2018. https://doi. org/10.1097/SLE.0000000000000542 [Epub ahead of print] PubMed PMID: 29889110.

14. Committee of Thyroid Surgeons of the Chinese Association of Physicians, Thyroid Surgery Committee, Chinese medical doctor association. Expert consensus on parathyroid protection in thyroid surgery. Chinese J Prac Surg. 2015;35(7):731-6. https://doi.org/10.7504/CJPS.ISSN1005-2208.2015.07.11.

15. Dionigi G, Van Slycke S, Rausei S, Boni L, Dionigi R. Parathyroid function after open thyroidectomy: a prospective randomized study for ligasure precise versus harmonic FOCUS. Head Neck. 2013;35(4): 562-7. https://doi.org/10.1002/hed.23005 Epub 2012 Jun 19. PubMed PMID: 22715020.

16. Zhang D, Caruso E, Sun H, Anuwong A, Tufano R, Materazzi G, Dionigi G, Kim HY. Classifying pain in transoral endoscopic thyroidectomy. J
Endocrinol Investig. 2019;42(11):1345-51. https://doi.org/10.1007/s40618019-01071-0 Epub 2019 Jun 11. PubMed PMID: 31187465.

17. Zhang D, Zhang J, Dionigi G, Li F, Wang T, Li H, Liang N, Sun H. Recurrent laryngeal nerve morbidity: lessons from endoscopic via bilateral areola and open thyroidectomy technique. World J Surg. 2019;43(11):2829-41. https://doi.org/10.1007/s00268-019-05092-x PubMed PMID: 31367782

\section{Publisher's Note}

Springer Nature remains neutral with regard to jurisdictional claims in published maps and institutional affiliations.
Ready to submit your research? Choose BMC and benefit from:

- fast, convenient online submission

- thorough peer review by experienced researchers in your field

- rapid publication on acceptance

- support for research data, including large and complex data types

- gold Open Access which fosters wider collaboration and increased citations

- maximum visibility for your research: over $100 \mathrm{M}$ website views per year

At $\mathrm{BMC}$, research is always in progress.

Learn more biomedcentral.com/submissions 